\title{
Amniotic fluid optical density at spontaneous onset of labour and it's correlation with gestational age, birth weight and functional maturity of newborn
}

\author{
Subha S. Sengodan*, Santhya Velumani \\ Department of Obstetrics and Gynecology, Government Kumarmangalam, Medical College Hospital, Salem, Tamil \\ Nadu, India
}

Received: 29 September 2020

Revised: 05 November 2020

Accepted: 06 November 2020

\section{*Correspondence:}

Dr. Subha S. Sengodan,

E-mail: drppsamysubha@gmail.com

Copyright: (c) the author(s), publisher and licensee Medip Academy. This is an open-access article distributed under the terms of the Creative Commons Attribution Non-Commercial License, which permits unrestricted non-commercial use, distribution, and reproduction in any medium, provided the original work is properly cited.

\begin{abstract}
Background: Respiratory distress is the common cause of neonatal morbidity and mortality. Babies born even at 40 weeks of gestation developed respiratory distress. The maturity of newborn is independent of gestational age and birth weight of newborn. In this study amniotic fluid optical density (AFOD) is correlated with the functional maturity of newborn.

Methods: In this study, hundred singleton pregnant women who underwent first trimester scan and crown rump length estimation, and who were on spontaneous labor were selected for this observational study. Under aseptic precautions AF samples were collected while doing amniotomy with $2 \mathrm{ml}$ disposable syringe, also collected during caesarean section after careful hysterotomy from the bulging membranes. Amniotic fluid optical density studied with spectrometer at $650 \mathrm{~nm}$. Birth weights were recorded for all the babies. Babies are also looked for the respiratory distress, NICU admission.

Results: In this study, respiratory distress was reported in $28 \%$ of newborns whereas $72 \%$ of newborns did not have distress. In the present study, $27 \%$ of newborns were admitted in NICU where as $73 \%$ of the newborns were on mother's side following delivery. Babies with AFOD $0.98 \pm 0.27$ were functionally mature, skin was pleased brown in colour with little vernix, none of them had respiratory distress. Amniotic fluid optical density $<0.4$ developed respiratory distress.
\end{abstract}

Conclusions: Amniotic fluid optical density is a simple method to assess the functional maturity of newborn.

Keywords: AFOD, Functional maturity, Respiratory distress

\section{INTRODUCTION}

Respiratory distress syndrome remains a common cause of neonatal morbidity and mortality. The pulmonary system is among the last of the fetal organ system to mature both functionally and structurally.

Pulmonary surfactant increases the lung compliance and prevents the collapse of alveoli during expiration. Biochemical analysis of LS ratio of 2:1 and phosphatidyl glycerol indicates pulmonary maturity. ${ }^{1,2}$ Among the biophysical methods, bubble formation tests, optical density at $650 \mathrm{~nm}$, flourescense polarisation lamellar body concentration helps in determining the fetal lung maturity. $^{2-6}$

Gestational age at delivery is unique to fetomaternal unit. $^{7}$ One of the most important preventive measures in obstetrics is the individual evaluation of most appropriate time to terminate the pregnancy. ${ }^{8}$ It is a conventional degree that babies born between 37-40 weeks are completely mature. Even after 40 weeks full term, an evidence of $0.25 \%$ RDS has been recorded. About $0.05 \%$ who were delivered electively between $37-40$ weeks 
required mechanical ventilation. ${ }^{9}$ The lung skin interaction by the surfactant causes vernix detachment, increases amniotic fluid turbidity. ${ }^{10,11}$

Though there are several techniques practiced in recent times to assess the maturity of fetus, role of amniotic fluid optical density (AFOD) in assessing the gestational age and functional maturity of newborn has been reported in several researches. ${ }^{12-14}$ Amniotic fluid absorbance at $650 \mathrm{~nm}$ is considered as a standard investigation for lung maturity evaluation. ${ }^{15}$ Even the low birth weight babies if functionally mature can be managed at home. ${ }^{16}$ In our study we confirm this phenomenon in terms of AFOD which measures lung maturity, skin maturity as well as biological age. Hence this study was conducted to correlate the AFOD at spontaneous onset of labour with gestational age, birth weight and functional maturity of newborn.

\section{Aims and objectives}

To establish the correlation between amniotic fluid optical density (AFOD) with gestational age, birth weight and functional maturity of newborns and to study the functional maturity of the newborns, especially in terms of lung maturity by means of presence or absence of respiratory distress in babies born out of spontaneous labour.

\section{METHODS}

A prospective study conducted on hundred antenatal women, admitted for delivery in GMKMCH, Salem.

\section{Duration of study:}

July 2019 to December 2019.

\section{Ethical committee approval}

Ethical committee approval was obtained for this study to find the correlation between amniotic fluid optical density with gestational age, birth weight and functional maturity of the new born among antenatal mothers attending inpatient department of Obstetrical and Gynecology, from the ethics committee.

\section{Inclusion criteria}

Women who underwent first trimester scan and crown rump length estimation and women with regular menstrual cycles who underwent USG at less than 20 weeks gestation which is in agreement with the gestation age calculated from the last menstrual period.

\section{Exclusion criteria}

Blood stained and meconium stained amniotic fluid samples, intrauterine growth restriction, premature rupture of membranes, multiple pregnancies.
Under aseptic precautions, amniotic fluid samples were collected while doing amniotomy with a sterile syringe. Amniotic fluid samples were also collected at cesarean section, after careful incision in the uterus from the bulging membranes. Minimum $2 \mathrm{ml}$ of amniotic fluid transferred to the plain test tube. Amniotic fluid optical density (AFOD) was measured using spectrometer. The wavelength was set at $650 \mathrm{~nm}$, first the control test tube with water was read by the spectrometer followed by the amniotic fluid sample. The amniotic fluid optical density (AFOD) was shown immediately as digital number in the spectrometer.

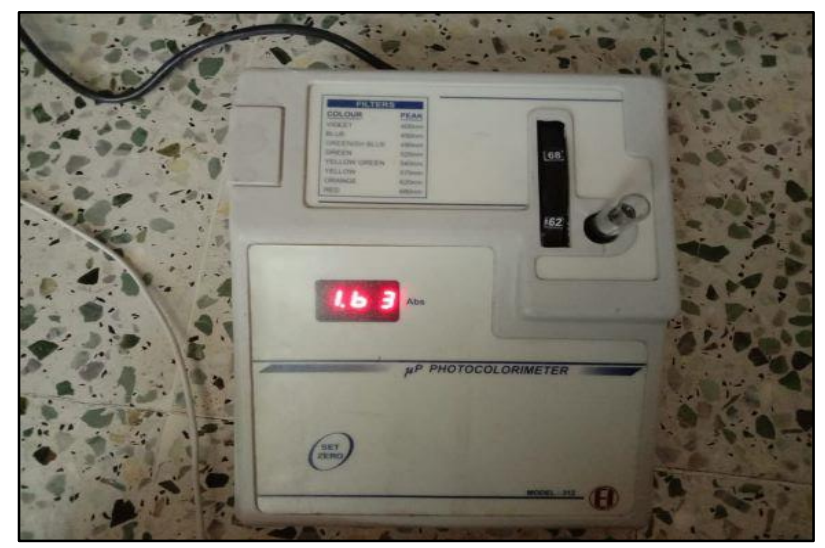

Figure 1: Spectrometer with test tube containing amniotic fluid.

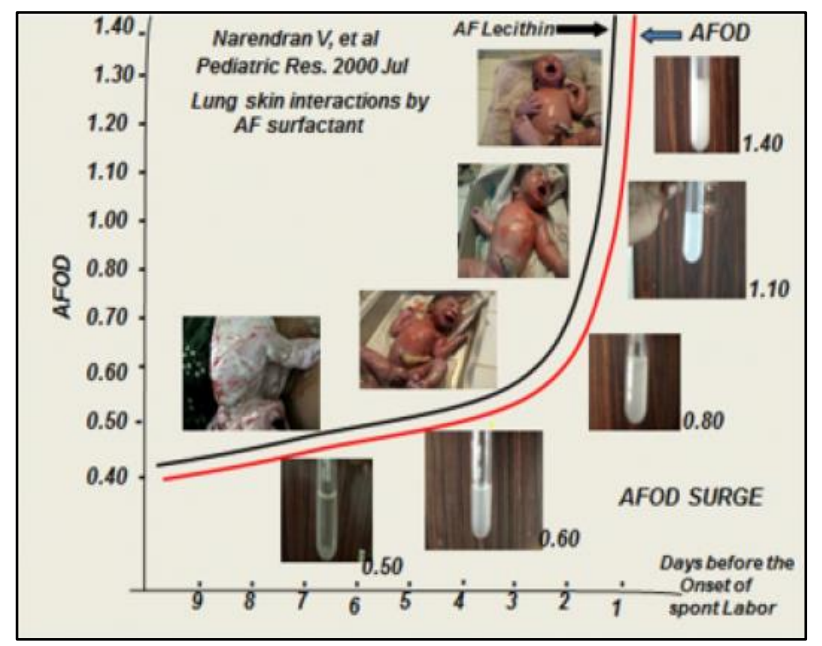

Figure 2: AFOD levels and fetal maturity.

Birth weights were recorded for all the babies by electronic weighing machine. APGAR scores at one minute and 5 minute were obtained. Babies were observed for clinical signs of respiratory distress. Clinical signs of respiratory distress $(\mathrm{RR}>60$, grunting, retraction of ribs/sternum, low $\mathrm{SPO}_{2}$ requiring $\mathrm{O}_{2}$ for more than 2 hours (to exclude transient tachypnea of newborn), chest x-ray findings after 24 hours were suggestive of RDS. Factors like sepsis, gestational diabetes mellitus, pneumonia, meconium aspiration, congenital anomalies were excluded. 


\section{Data analysis}

The data was entered in excel sheet and analyzed using statistical package for social sciences (SPSS- version 17). Descriptive statistics with mean, standard deviation (SD) and proportions (\%) were calculated for continuous variables. To test the hypothesis chi Square test, independent sample $\mathrm{t}$ test and ANOVA were used appropriately. $\mathrm{P}$ value $<0.05$ was considered as statistically significant.

\section{RESULTS}

In this study, there were hundred participants included. Among them majority (47\%) of them were in the age group of 21-25 years followed by 26-30 years (33\%), less than or equal to 20 years (15\%) and 31-35 years (5\%).

Table 1: Proportion of participants in different gestational age.

\begin{tabular}{|c|c|}
\hline Gestational age & Percentage \\
\hline 33-33 weeks + 6 days & 5.0 \\
\hline 34-34 weeks + 6 days & 11.0 \\
\hline 35-35 weeks + 6 days & 5.0 \\
\hline 36-36 weeks + 6 days & 26.0 \\
\hline 37-37 weeks + 6 days & 20.0 \\
\hline 38-38 weeks + 6 days & 23.0 \\
\hline 39-39 weeks + 6 days & 5.0 \\
\hline 40-40 weeks + 6 days & 5.0 \\
\hline
\end{tabular}

Spontaneous labour occurred most commonly in the gestational age group 36-36 weeks +6 days of gestation (26\%) followed by $38-38$ weeks +6 days of gestation (23\%), 37-37 weeks + 6 days of gestation (20\%) and 3434 weeks +6 days of gestation $(11 \%)$. Also $5 \%$ of cases had spontaneous labour in the gestational age group 3333 weeks +6 days, $35-35$ weeks +6 days, 39-39 weeks + 6 days of gestation and 40-40 weeks +6 days of gestational age. In this study, respiratory distress was reported in $28 \%$ of newborns whereas $72 \%$ of newborns did not have distress.

Table 2: Association between gestational age and respiratory distress.

\begin{tabular}{|c|c|c|c|}
\hline \multirow{2}{*}{$\begin{array}{l}\text { Gestational age } \\
\text { (in weeks) }\end{array}$} & \multicolumn{2}{|c|}{ Respiratory distress } & \multirow{2}{*}{ P value } \\
\hline & Present & Absent & \\
\hline 33-33+6 days & 5 & 0 & \multirow{9}{*}{$0.000^{*}$} \\
\hline 34-34+6 days & 6 & 5 & \\
\hline 35-35+6 days & 3 & 2 & \\
\hline 36-36+6 days & 3 & 23 & \\
\hline 37-37+6 days & 2 & 18 & \\
\hline 38-38+6 days & 7 & 16 & \\
\hline 39-39+6 days & 0 & 5 & \\
\hline 40-40+6 days & 2 & 3 & \\
\hline Total & 28 & 72 & \\
\hline
\end{tabular}

Table 3: Difference in mean AFOD with respect to respiratory distress.

\begin{tabular}{|c|c|c|c|}
\hline Variable & $\begin{array}{l}\text { Respiratory } \\
\text { distress }\end{array}$ & Mean \pm SD & P value \\
\hline \multirow{2}{*}{$\begin{array}{l}\text { Amniotic fluid } \\
\text { optical density }\end{array}$} & Present & $0.4 \pm 0.1$ & \multirow{2}{*}{$0.000 *$} \\
\hline & Absent & $1.2 \pm 0.1$ & \\
\hline
\end{tabular}

*Significant

Mean difference in AFOD among the cases with and without respiratory distress was found to be $0.4 \pm 0.1$ and $1.2 \pm 0.1$, respectively. The difference in AFOD with respect to respiratory distress was found to be statistically significant in this study with a p value of 0.000 .

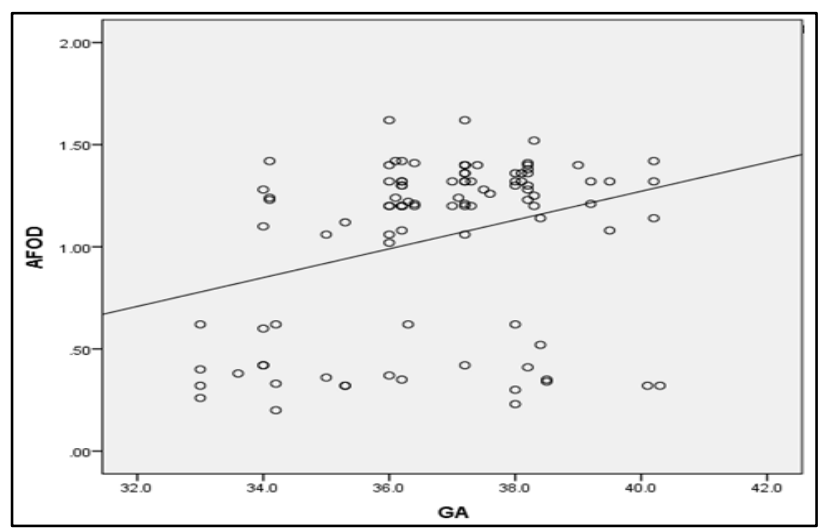

Figure 3: Correlation between gestational age and AFOD.

\section{DISCUSSION}

Gestational age by itself does not always exclude the possibility of respiratory distress syndrome because literature has reported prevalence of RDS after 40 weeks of gestation as $0.25 \% .^{17,18}$ Though the percentage is small, the number increases to significant proportions when extrapolated to larger populations which are avoidable. American College of Obstetricians and Gynecologists guidelines recommend the obstetricians to confirm fetal pulmonary maturity prior to elective delivery less than 39 weeks gestation. ${ }^{19}$ ACOG recommends the AFOD value $>0.15$ of a centrifuged amniotic fluid sample to confirm lung maturity. The onset of spontaneous labour takes place at AFOD value around $0.98 .^{21}$

In this study, we observed that newborns with AFOD value $<0.40$ developed RDS. The findings are in accordance with the previous studies, AFOD represents indirectly the amount of surfactant. ${ }^{21,22}$ Hence severity depends on the how low the AFOD value is or in other words how low the surfactant phospholipids are and not always how low the chronological age is. There could be other factors accounting for less severity of RDS like trial of labour or unknown constitutional factors at advanced gestational age despite low surfactant levels as revealed by low AFOD values. ${ }^{23}$ However the severity could be 
more than expected on rare occasions. ${ }^{24-26}$ Exact measurements of AFOD is possible in AFI value of 9$16 .{ }^{27}$ Ram et al reported mean optical density of $1.03 \pm 0.31$ in babies devoid of RDS. ${ }^{28,29}$ Babies With AFOD $0.98 \pm 0.27$ are functionally mature, skin was pleased brown in colour with little vernix, none of them had respiratory distress. ${ }^{30}$ Amniotic fluid optical density $<0.4$ developed respiratory distress. ${ }^{31,32}$

In our study, mean difference in AFOD among the cases with and without respiratory distress was found to be $0.4 \pm 0.1$ and $1.2 \pm 0.1$, respectively. The difference in AFOD with respect to respiratory distress was found to be statistically significant in this study. In this study, it was found that amniotic fluid optical density levels were high among the newborns with better APGAR score at five minutes. Thus shows a significant positive correlation between APGAR at five minutes and amniotic fluid optical density.

The onset of labour is more closely related to fetal functional maturity than either gestational age or birth weight. ${ }^{33}$ The gestational age at delivery is unique to each feto-maternal unit The understanding of AFOD prevents iatrogenic prematurity and complications of postmaturity thereby optimizing labour.

Limitation of this study is only 100 amniotic fluid samples are studied, further studies are needed.

\section{CONCLUSION}

In this study we conclude that each fetus has got its own maturity potential amniotic fluid optical density (AFOD) was found to be significantly associated with functional maturity of newborn. It was found that AFOD increases with gestational age.

AFOD is higher among the newborns with better APGAR score. In our study babies with AFOD $<0.40$ developed respiratory distress irrespective of gestational age and birth weight of newborn. Babies with AFOD 1.2 \pm 0.1 are functionally mature and did not develop respiratory distress irrespective of gestational age and birth weight of newborn, which is found to be statistically significant. Induction of labour needs to be reviewed in lights of AFOD which determines the preparedness of labour and hence the biological gestational age that is more relevant than the estimated date of confinement (EDC).

Funding: No funding sources Conflict of interest: None declared

Ethical approval: The study was approved by the Institutional Ethics Committee

\section{REFERENCES}

1. Tsao FH, Zachman RD. Use of quantitative amniotic fluid phosphatidylglycerol as a criterion for fetal lung maturation. Am J Perinatol. 1992 Jan;9(01):347.

2. Dubin SB. The laboratory assessment of fetal lung maturity. Am J Clin Pathol. 1992;97(6):836-49.

3. Hagen ED, Link JC, Arias FE. A comparison of the accuracy of the TDx-FLM assay, lecithinsphingomyelin ratio, and phosphatidylglycerol in the prediction of neonatal respiratory distress syndrome. Obstet Gynecol. 1993;82(6):1004-8.

4. Ruch AT, Lenke RR, Ashwood ER. Assessment of fetal lung maturity by fluorescence polarization in high-risk pregnancies. J Reprodu Med. 1993;38(2):133-6.

5. Fakhoury G, Daikoku NH, Benser J, Dubin NH. Lamellar body concentrations and the prediction of fetal pulmonary maturity. Am J Obstet Gynecol. 1994;170(1):72-6.

6. Salmona M, Diomede L, Moro G, Minoli I, Bernini S, Agosti S. Fetal lung maturity evaluation with fluorescence polarization of the amniotic fluid. Jo Perinat Med. 1993;21(5):349-54.

7. Popkin DR, Peddlr LJ. Women's Health TodayPerspectives on current research and Clinical Practice: The proceedings of XIV World congress of Obstetrics and Gynecology. In: Impact of Imaging in Obstetrics and Gynecology- Prediction of birthdate and newborns state. 1st edn. New York: Parthenon publishing Group; 1994:246.

8. Morrison JJ, Rennie JM, Milton PJ. Neonatal respiratory morbidity and mode of delivery at term: influence of timing of elective caesarean section. $\mathrm{Br}$ J Obstet Gynaecol. 1995;102:101-6.

9. Wax JR, Herson V, Carignan E, Mather J, Ingardia CJ. Contribution of elective delivery to severe respiratory distress at term. Am J Perinatol. 2002;19(2):81-6.

10. Narendran V, Randall WR, William LP, Steven BH. Interaction between pulmonary surfactant and vernix: a potential mechanism for induction of amniotic fluid turbidity. J Pediatr Res. 2000;48:1204.

11. Klimek R. A new score for postnatal clinical assessment of fetal maturity in newborn infants. Int $\mathbf{J}$ Gynecol Obstet. 2000;71:101-5.

12. Bhatnagar PK. Study of low birth weight neonates. Med J Armed Forces India. 2000;56:293-5.

13. Klimek R. The use in obstetrics of quantum theory as well as modern technology to decrease the morbidity and mortality of newborns and mothers during iatrogenic induced delivery. Neuroendocrinol Letters. 2001;22:5-8.

14. Zanardo V, Simbi AK, Franzoi M, Solda G, Salvadori A, Trevisanuto D. neonatal respiratory morbidity risk and mode of delivery at term: influence of timing of elective caesarean delivery. Acta Paediatr. 2004;93:643-7.

15. Cunningham G, Leveno KJ, Bloom SL, Hauth JC, Gilstrap LC, Wenstorm KD. Diseases and injuries of Fetus and New born. In: Willaims Text book of 
Obstetrics. 22nd edn. New York: McGraw-Hill Medical Publishing Division; 2005:367.

16. Park K. Child Survival and Safe Motherhood Programme (CSSM). In: Park's Text book of Preventive and Social Medicine. 18th edn. Jabalpur: Banarasidas Bhanot Publishers; 2005:344.

17. Abbas M, Bakr A. Severe respiratory distress in Term infants born electively at high altitude. BMC Pregnancy Childbirth. 2006;6:1-4.

18. Peter S, Rhiannon W, Ian R. Antenatal betamethasone and incidence of neonatal respiratory distress after elective caesarean section: (ASTECS) pragmatic randomized trial. Obstet Gynecol Survey. 2006;61:157-8.

19. ACOG committee opinion no. 394. Cesarean delivery on maternal request. Obstet Gynecol. 2007;11096:1501.

20. ACOG educational bulletin. ACOG Practice Bulletin No. 97: Fetal Lung Maturity. Obstet Gynecol. 2008;112(3):717-26.

21. Luo G, Norwitz ER. Revisiting amniocentesis for fetal lung maturity after 36 weeks' gestation. Rev Obstet Gynecol. 2008;1(2):67.

22. Ram S. Amniotic fluid optical density at spontaneous onset of labor and its correlation with gestational age, birth weight, functional maturity and vernix caseosa of new born. Calicut Med J. 2009;7(4).

23. Kamath BD, Todd JK, Glazner JE, Lezotte D, Lynch AM. Neonatal outcomes after elective cesarean delivery. Obstet Gynecol. 2009;113(6):1231-8.

24. Tita ATN, Landon MB, Catherine Y, Lai SY, Leveno, Varner MW, et al. Timing of elective repeat cesarean delivery at term and neonatal outcomes. N Engl J Med. 2009;360:112-20.

25. Raba G, Baran P. Obstetric outcomes in oxytocinrelated and spontaneous deliveries- analysis of 2198 cases. Ginekol Pol. 2009;80(7):508-11.
26. Al-Zirqi I, Vangen S, Forsén L, Stray-Pedersen B. Effects of onset of labor and mode of delivery on severe postpartum hemorrhage. Am J Obstet Gynecol. 2009;201(3):273.e1-9.

27. Shankar R Sandya R. Role of echogenic amniotic fluid particles and optical density in prediction of RDS and labor. Internet J Med Update. 2010;5(1):311.

28. Ram SH, Ram S. Role of echogenic amniotic fluid particles and optical density in prediction of respiratory distress syndrome and labor. Internet $\mathbf{J}$ Med Update. 2010;5(1).

29. Samartha ram h, sandhya ram s, amniotic fluid optical density (AFOD) surge coincides with the onset of spontaneous term labor. Paper presented at $55^{\text {th }}$ AICOG-2012.

30. Hanuman RK. Correlation between amniotic fluid optical density (AFOD) and functional maturity status of the newborn at caesarean delivery in GDM. IOSR J Dent Med Sci. 2014;13(5V):12-6.

31. Ram SH, Ram SD. Individualized term for each fetus: From surge in amniotic fluid optical density (AFOD). Internet J Gynecol Obstet. 18(1):1-6.

32. Rao NYL, Isuapalli V, Samyukta Ila S. Amniotic fluid optical density (AFOD) correlates with the lung maturity as well as complete maturity of the fetus- a clinical observational study. IAIM. 2015;2(8):30-7.

33. Ram HS, Samyuktha IS, Nagasree V. Outcomes of induction of labor with mature and premature amniotic fluid optical density (AFOD): a preliminary case control study. Trop J Obstet Gynaecol. 2019;36(2):206-1.

Cite this article as: Sengodan SS, Velumani S. Amniotic fluid optical density at spontaneous onset of labour and it's correlation with gestational age, birth weight and functional maturity of newborn. Int J Reprod Contracept Obstet Gynecol 2020;9:5060-4. 